\title{
Pemikiran Ali Ahmad Madkur tentang Ilmu Pengetahuan dalam Islam
}

\author{
Asep Sopian', Hendri Juhana ${ }^{2}$, Izzuddin Mustafa ${ }^{3}$ \\ 1,2,3Universitas Islam Negeri Sunan Gunung Djati Bandung, Indonesia \\ E-mail: sopianasep8793@gmail.com, hendrijuhana1@gmail.com, izzuddin@uinsgd.ac.id
}

\section{Article Info \\ Article History \\ Received: 2021-12-27 \\ Revised: 2022-01-22 \\ Published: 2022-02-10}

Keywords:

Perspective;

Ali Ahmad Madkur;

Knowledge;

Islam.

\begin{abstract}
This research is a study of Ali Ahmad Madkur's thoughts on science in Islam. This type of research is qualitative with library research method. The results of the study show that in the Islamic education system, the curriculum is known as "manhaj" which means "the path of light". The path that must be traversed by educators to develop students' knowledge skills and attitudes, in his work that Ali Ahmad Madkur talks about one of the fundamental aspects of education, namely the curriculum aspect. To discuss further about the curriculum, the authors of this book first discuss the various fundamental theoretical foundations that are an integral part of the conception of the curriculum. These aspects include basic understanding of education, philosophy and education, educational theories, the role of science in education. Regarding the subject matter related to the curriculum, the book with the title tabiah ma'rifah al-tashawwur al-islami provides a comprehensive picture of science from an Islamic perspective. An understanding based on an understanding of the Qur'an and Sunnah, then on a historical study of the thoughts of the scholars, studies of Muslim figures who have a concentration on education, as well as various researches from scientists related to the object of Islamic education.
\end{abstract}

\begin{tabular}{l}
\hline Artikel Info \\
\hline Sejarah Artikel \\
Diterima: $2021-12-27$ \\
Direvisi: 2022-01-22 \\
Dipublikasi: $2022-02-10$
\end{tabular}

Kata kunci:

Pemikiran; Ali Ahmad Madkur; Pengetahuan; Islam.

\section{PENDAHULUAN}

Pendidikan merupakan kebutuhan baik bagi individu maupun bagi sebuah bangsa, ukuran kemajuan sebuah bangsa, bahkan dilihat sejauh mana kemajuan pendidikannya hal inilah yang membuat pendidikan memiliki peran besar bagi kehidupan manusia, bahkan menurut (Tanjung, 2020) bahwa tanpa pendidikan, manusia terancam dengan kemiskinan dan kelaparan. Pendidikan adalah solusi bagi berbagai macam permasalahan yang dihadapai bangsa, negara dan masyarakat serta individu (Apiyani, 2022). Akan tetapi jika pendidikan yang diselenggara- kan bersifat parsial, kurikulum yang dibuat tidak mengandung berbagai aspek, dimensi dan nilai yang bersentuhan dengan fikir, ruh dan jasad yang sumbernya dari agama, maka gagal penyelenggaraan pendidikan tersebut karena tidak syamilah dan mutakamilah. Oleh karena itu di Indonesia sampai saat ini pendidikan tidak pernah selesai untuk diperbincangkan tidak hanya oleh ahli pendidikan, kalangan politikus, penguasa, pejabat pemerintah, bahkan ibu-ibu rumah tangga ikut serta membicarakannya, hal tersebut sangat mungkin sekali diperbincangkan disebabkan beban biaya sekolah yang semakin 
mahal. Menurut (Tafsir, 2012) menyatakan bahwa, pendidikan adalah unfinished agenda, karena dari sanalah awal dan berakhir segalanya, suatu bangsa akan tinggi martabatnya dihadapan bangsa lain karena pendidikan, begitupun sebaliknya martabat suatu bangsa akan turun bahkan terpuruk karena pendidikan. Berbeda halnya apabila yang dibicarakan itu masalah ekonomi, politik, budaya, ia berakhir keaktualannya seiring dengan berakhirnya masalah yang dihadapi oleh masyarakat.

Allah menciptakan alam semesta ini untuk kesejahteraan umat manusia, manusia disuruh untuk mengelola alam ini agar dapat dimanfaatkan guna keperluan hidup mereka, untuk mengelola alam ini tentu saja diperlukan akal, Allah menyuruh manusia menggunakan akalnya (Darmayani, 2021), islam juga menghendaki umatnya untuk memiliki ilmu pengetahuan, baik ilmu pegetahuan agama maupun ilmu pengetahuan umum, dalam pandangan Islam, ilmu itu tergolong suci. Menurut (Arifudin, 2020) bahwa ilmu merupakan barang yang sangat berharga bagi kehidupan seseorang, ilmu itu bagaikan lampu atau cahaya, bahwa tidak dapat seseorang berjalan di malam yang gelap kecuali dengan lampu, demikian pula halnya tidak dapat seseorang membedakan yang baik dengan yang buruk, kecuali dengan ilmu. Pendidikan adalah usaha atau proses perubahan dan perkembangan manusia menuju ke arah yang lebih baik dan sempurna (Arifudin, 2021), adanya ungkapan bahwa pendidikan merupakan proses perbaikan dan menuju kesempurnaan, hal itu mengandung arti bahwa pendidikan bersifat dinamis karena jika kebaikan dan kesempurnaan tersebut bersifat statis maka ia akan kehilangan nilai kebaikannya. Gerak dinamis yang continue telah dilakukan oleh nabi dan membuahkan hasil berupa pembangunan peradaban Islam yang tinggi dan dihormati oleh masyarakat dunia saat itu dan bahkan hingga sekarang ini.

Pendidikan Islam pada hakikatnya adalah proses perubahan menuju arah positif, dalam konteks sejarah perubahan yang positif ini adalah jalan Tuhan yang telah dilaksanakan sejak zaman Nabi Muhammad. Pendidikan Islam dalam konteks perubahan ke arah positif ini identik dengan kegiatan dakwah yang biasanya dipahami sebagai upaya untuk menyampaikan ajaran Islam kepada masyarakat (Na'im, 2021), sejak wahyu pertama diturunkan dengan program Iqra" (membaca) pendidikan Islam praksis telah lahir, berkembang dan eksis dalam kehidupan umat Islam yakni sebuah proses pendidikan yang melibatkan dan menghadirkan Tuhan. Ali Ahmad Madkur mengatakan bahwa pendidikan merupakan proses yang sangat komplek, teratur dan memiliki kaidah-kaidah tertentu (Madkur, 2002). Pendidikan itu tidak akan terpisahkan dengan hidup dan kehidupan umat manusia karena merupakan kebutuhan hidup, salah satu fungsi sosial, bimbingan, sebagai sarana pertumbuhan yang mempersiapkan dan membukakan serta membentuk disiplin hidup (Dewey, 1966). Pada intinya pendidikan adalah sebuah kegiatan yang dilakukan dengan sengaja dan terencana yang dilaksanakan oleh orang dewasa yang memiliki ilmu dan keterampilan kepada anak didik, demi terciptanya insan kamil dengan pendidikan itu pula seesorang mampu bertaqorrub kepada Allah (Fatiyah, 1986).

\section{METODE PENELITIAN}

Sesuai dengan karakteristik masalah yang diangkat dalam makalah ini maka penulis menggunakan Metode Riset kualitatif, yaitu menekankan analisanya pada data deskriptif berupa kata-kata tertulis yang diamati. Pendekatan kualitatif penulis gunakan untuk menganalisis pemikiran Ali Ahmad Madkur tentang ilmu pengetahuan dalam islam, maka dengan sendirinya penganalisaan data ini lebih difokuskan pada Penelitian Kepustakaan (Library Research), yakni dengan membaca, menelaah dan mengkaji buku-buku dan sumber tulisan yang erat kaitannya dengan masalah yang dibahas (Supriani, 2022). Metode yang digunakan dalam kajian ini menggunakan metode atau pendekatan kepustakaan (library research), menurut Zed dalam (Rahayu, 2020) bahwa studi pustaka atau kepustakaan dapat diartikan sebagai serangkaian kegiatan yang berkenaan dengan metode pengumpulan data pustaka, membaca dan mencatat serta mengolah bahan penelitian.

Jenis penelitian ini adalah penelitian kualitatif, menurut Ibnu dalam (Nasser, 2021) penelitian kualitatif adalah suatu penelitian yang datanya dinyatakan dalam bentuk verbal dan dianalisis tanpa menggunakan teknik statistik. Berdasarkan beberapa definisi penelitian kualitatif di atas dapat disimpulkan bahwa penelitian kualitatif adalah suatu penelitian yang datanya dinyatakan dalam bentuk verbal, tidak menggunakan angka dan analisisnya tanpa menggunakan teknik statistik.

1. Objek Penelitian

Menurut (Arifudin, 2018) bahwa dalam penelitian objek penelitian dibagi menjadi, yaitu objek formal dan objek material, objek 
formal dalam penelitian ini berupa data yaitu data yang berhubungan dengan pemikiran Ali Ahmad Madkur tentang ilmu pengetahuan dalam islam. Sedangkan objek materialnya berupa sumber data dalam hal ini adalah pemikiran Ali Ahmad Madkur tentang ilmu pengetahuan dalam islam.

2. Waktu Penelitian

Penelitian ini dilaksanakan pada bulan oktober sampai dengan desember tahun 2021.

3. Teknik Pengumpulan Data

Pengumpulan data yang dilakukan dengan menggunakan teknik dokumentasi yaitu mengadakan survey bahan kepustakaan untuk mengumpulkan bahan-bahan dan studi literatur yakni mempelajari bahan-bahan yang berkaitan dengan objek penelitian. Teknik pengumpulan data menurut (Bahri, 2021) mengemukakan bahwa merupakan langkah yang paling strategis dalam penelitian karena tujuan untama dari penelitian adalah mendapatkan data. Terdapat beberapa cara atau teknik dalam mengumpulkan data, diantaranya adalah observasi dan dokumentasi.

4. Alat Pengumpulan Data

Dalam penelitian ini, penulis akan menggunakan metode dokumentasi sebagai alat untuk pengumpul data karena penelitian ini adalah penelitian kepustakaan. Dengan kata lain, menurut (Tanjung, 2019) bahwa teknik ini digunakan untuk menghimpun data-data dari sumber primer maupun sekunder.

5. Teknik Analisis Data

Analisis data tidak saja dilakukan setelah data terkumpul, tetapi sejak tahap pengumpulan data proses analisis telah dilakukan. Penulis menggunakan strategi analisis "kualitatif", strategi ini dimaksudkan bahwa analisis bertolak dari data-data dan bermuara pada kesimpulan-kesimpulan umum. Berdasarkan pada strategi analisis data ini dalam rangka membentuk kesimpulan-kesimpulan umum analisis dapat dilakukan menggunakan kerangka pikir "induktif", menurut (Sugiyono, 2015) bahwa metode pembahasan menggunakan metode deskriptif-analisis, yaitu menjelaskan serta mengelaborasi ide-ide utama yang berkenaan dengan topik yang dibahas, kemudian menyajikannya secara kritis melalui sumber-sumber pustaka primer maupun skunder yang berkaitan dengan tema.

6. Prosedur Penelitian

Data pada penelitian ini dicatat, dipilih dan kemudian diklasifikasikan sesuai dengan kategori yang ada, pendekatan yang diguna- kan adalah pendekatan deskriptif analitis. Menurut (Arifudin, 2019) bahwa deskriptif analitis (descriptive of analyze research), yaitu pencarian berupa fakta, hasil dari ide pemikiran seseorang melalui cara mencari, menganalisis, membuat interpretasi serta melakukan generalisasi terhadap hasil penelitian yang dilakukan. Prosedur penelitian ini (Tanjung, 2022) adalah untuk menghasilkan data deskriptif yang berupa data tertulis setelah melakukan analisis pemikiran (content analyze) dari suatu teks. Setelah penulis mengumpulkan bahan-bahan yang berhubungan dengan masalah yang akan di bahas dalam penelitian ini, kemudian penulis menganalisis dan menarasikan untuk diambil kesimpulan.

\section{HASIL DAN PEMBAHASAN}

Dalam pembahasan ini akan dibahas tentang Riwayat Singkat Hidup Ali Ahmad Madkur, Tujuan Akhir dari Ilmu Pengetahuan adalah Penerapan Kurikulum Allah, Konsep pengalaman dalam kurikulum pendidikan Islam, Pokok-Pokok Pemikiran.

1. Riwayat Singkat Hidup Ali Ahmad Madkur Ali Ahmad Madkur adalah salah satu tokoh pendidikan Islam kontemporer di Timur Tengah adalah Ali Ahmad Madkur. Ia dilahirkan di kota Mesir (Qahirah). Gelar sarjana bidang Pendidikan beliau peroleh di Al-Azhar University Mesir. Sekarang menjadi guru besar (Profesor) di bidang pengembangan kurikulum. Sebelumnya pada tahun 2001 ia dipercaya sebagai Dekan Fakultas Tarbiyah di Universitas Sultan Qobus Oman, sebagai seorang profesor di bidang kurikulum dan pendidikan Ahmad Madkur dikenal aktif memberikan materi seminar ilmiah di dalam dan di luar negeri yang berkenaan dengan kependidikan dan bahasa dibeberapa perguruan tinggi di timur tengah.

2. Tujuan Akhir dari Ilmu Pengetahuan

Tujuan dari ilmu pengetahuan adalah agar manusia mampu membangun dan memajukan kehidupan di bumi sesuai dengan aturan Allah, pengetahuan sejati menurut Islam adalah pengetahuan yang didasarkan pada ketakwaan kepada Allah beserta segala konsekwensi yang sesuai dengan aturan dan hukum Allah. Bertakwalah kalian kepada Allah, Allah senantiasa mengajari kalian, dan sesunggunya Allah Maha Mengetahui segalanya" (Baqarah: 282). Takwa dengan penger- 
tiannya yang komprehensif merupakan pondasi dari ilmu pengetahuan.

Berdasarkan hal itu, pengetahuan yang ditargetkan dalam kurikulum pendidikan Islam adalah pengetahuan yang mengarah pada perubahan kongkrit perilaku manusia di dalam kehidupan nyata (Hasbi, 2021), sedangkan pengetahuan teoritis semata yang tidak mempengaruhi perilaku manusia dalam kehidupan nyata tidak memberi manfaat dan tidak selaras dangan kurikulum pendidikan Islam. Islam menuntut adanya tindakan nyata yang didasarkan pada ilmu pengetahuan, sehingga pengetahuan yang telah didapatkan melahirkan motivasi yang kuat untuk merealisasikan maknanya dalam dunia nyata (Darmawan, 2021). Begitulah adanya pengetahuan ketuhanan yang diajarkan oleh Islam berbeda karakter dan jenisnya dengan pengetahuan ketuhanan pada masa jahiliah yang dianggap bukan pengetahuan, karena itulah ketika Islam mulai mengajar orangorang Arab dasar-dasar hakikat ketuhanan, ia tidak membangunnya di atas pengetahuan sebelumnya, bahkan ia mengoreksi pengetahuan tersebut, lebih jauh lagi Islam tidak menganggapnya sebagai pengetahuan. Islam mulai membangun di dalam hati mereka konsep kelihaian dengan dasar yang sama sekali baru.

3. Konsep pengalaman dalam kurikulum pendidikan Islam

Dalam kurikulum pendidikan Islam manusia belajar dengan menerima langsung dari Allah dan rasul-Nya, dengan mengamati jagat alam semesta yang ada sekelilingnya melalui praktik dan latihan serta melalui pengalaman experimental, terkait pengetahuan yang berhubungan dengan hakikat, norma, nilai-nilai ilahiah serta hal-hal lain yang berhubungan dengan karakteristik dan elemen umum kurikulum Islam, manusia menerimanya secara garis besarnya dari Allah SWT. Praktiknya bergantung pada tingkat penerimaan dan kesadaran masing-masing, tergantung pada kemampuan seseorang beradaptasi dengan semua itu dan pada pemenuhan persyaratan kongritnya, ketika manusia menerima semua ini dia menerimanya tanpa ada pengaruh dari keputusan sebelumnya dari sumber manapun, baik dari dirinya maupun dari sumber lain: "Kemudian Kami jadikan kamu berada di atas suatu syariat (peraturan) dari urusan (agama itu), Maka ikutilah syariat itu dan janganlah kamu ikuti hawa nafsu orang-orang yang tidak mengetahui." (al-Jatsiyah: 18)

4. Pokok-Pokok Pemikiran

a) Minhaj

Manhaj, nahaj atau minhaaj dari madah yang semuanya mempunyai satu makna. Dari segi bahasa manhaj ialah: "Jalan yang jelas, terang dan dikatakan juga (mengikut) jalan yang lurus atau mengikut sunnah". Minhaj atau manhaj, menurut bahasa Arab artinya jalan yang jelas dan terang (AlMisri., 1990). Allah Ta"ala berfirman yang artinya, "Untuk tiap umat di antara kamu, kami berikan aturan dan jalan yang terang" (Al-Maidah: 48), menurut istilah syar'i, manhaj ialah kaidah-kaidah dan ketentuanketentuan yang digunakan bagi setiap pelajaran-pelajaran ilmiyyah, seperi kaidahkaidah bahasa Arab, ushul, aqidah, ushul fiqih dan ushul tafsir di mana dengan ilmuilmu ini pembelajaran dalam islam beserta pokok-pokoknya menjadi teratur dan benar. Manhaj yang benar adalah jalan hidup yang lurus dan terang dalam beragama menurut pemahaman para sahabat Rasulullah shallallahu alaihi wa sallam "Barangsiapa yang menentang Rasul sesudah jelas kebenaran baginya dan mengikuti jalan yang bukan jalan-jalan orang-orang mukmin, kami biarkan ia leluasa dalam kesesatan yang Telah dikuasainya itu dan kami masukkan ia kedalam jahannam, dan jahannam itu seburuk-buruk tempat kembali." (al-Nisa": 115).

b) Ilmu dan Makrifah

Rhaghib Isfahani dalam kitab Al Mufradat menjelaskan, makrifat adalah ilmu, tetapi pengetahuan tentang suatu zat sesuatu (materi), sementara ma'rifat berhubungan dengan haq Ta'ala (non materi). Oleh karena itu makrifat tentang dzat Haq Taala hanya bisa dirasakan melalui atsar-atsarNYa (ciptaanNya), lebih lanjut Rhagib menjelaskan bahwa, kata (ilm) ilmu tidak dipakai untuk mengenal tuhan, sebagai contoh dalam bahasa arab kalimat Alima Zaidun Allah tidak dipakai, dikarenakan kata alima atau (ilm-berilmu) hanya di pakai pada sesuatu yang bisa kita rasakan dan sadari (melalui pancaindera), tetapi menggunakan kalimat (Arifa Zaidun Allah). Ketika kalimat Alima Allah pakai karena Allah sudah mengetahui hambahambaNya, oleh karena itu kalimat Arifa 
Allah tidak dipakai, dengan demikian pendapat Raghib, ma'rifat lebih lebih khusus. (akhash) dari ilmu dan dari sisi istilah antara irfan dan ilmu mempunyai perbedaan yang sangat jauh. Pada kenyataannya, penggunaan kata ilmu dan ma'rifat digunakan pada pembahasan yang menyerupai, bukan seperti yang dikatakan oleh Raghib, tentunya pembahasan ini akan kita bahas dalam pembahasannya sendiri yang dalam istilah khusus para ahli ma"rifat dan irfan. Insya Allah.

c) Islam tidak mengenal dikotomi ilmu agama dan ilmu umum

Pada prinsipnya, semua bidang ilmu dirumuskan dan dikembangkan dalam rangka memberikan kontribusi bagi upaya pengembangan fitrah (potensi) manusia, baik dalam posisinya sebagai hamba Allah maupun khalifatullah (pemegang amanat Allah di muka bumi), agar ia dapat berinteraksi secara aktif dan positif dengan lingkungannya, sekaligus turut membangun dan melestarikan kehidupan sesuai anjuran-Nya. Demikianlah sesungguhnya inti dan hakikat "ilmu agama (Islam)", baik yang berkaitan secara langsung dengan bidang ilmu-ilmu syari'at (agama) maupun ilmu-ilmu modern (umum) seperti fisika, kimia, teknik, dan sebagainya. Hal ini sebagaimana dinyatakan oleh banyak pemikir Muslim yang tidak sekedar tahu "teks-teks" keislaman, namun juga memahami "ruh atau spirit" yang terkandung di balik teks tersebut. Abul A'la al-Maududi misalnya, ia menyatakan: "Pada dasarnya, munculnya dikotomi keilmuan (ilmu agama dan ilmu umum) disebabkan adanya paradigma yang memisahkan antara masalah agama dan kehidupan. Pandangan ini sesungguhnya justru bertentangan dengan substansi ajaran Islam itu sendiri. Karena dalam Islam, persoalan agama bukanlah persoalan yang terpisah dari kehidupan. Alam semesta beserta segala isinya adalah milik Allah, demikian pula manusia yang ada di dalamnya. Sebagai hamba Allah, manusia dituntut mampu menjalani misi kehidupannya sesuai titah Allah, serta menghayati segala bentuk pengajaran-Nya (Al-Maududi, 1982).

Demikianlah sesungguhnya pemaknaan "agama" yang lebih tepat dan selaras dengan prinsip syariat Islam. Maka, ilmuilmu yang selama ini dianggap sebagai "ilmu dunia (umum)", pun pada hakikatnya juga merupakan "ilmu agama". Pembedaan ilmu menjadi 2 (dua) bagian yang saling terpisah, yakni: "ilmu agama" yang mengkaji persoalan ukhrawi di satu sisi, dan "ilmu umum" yang membahas persoalan duniawi di sisi yang lain, hanya akan mengantarkan kita pada asumsi bahwa antara agama dan kehidupan merupakan 2 (dua) hal yang sama sekali berbeda dan tidak memiliki keterkaitan. Kondisi inilah yang pada akhirnya mengakibatkan upaya sinkronisasi antara keduanya (ilmu agama dan ilmu umum) yang notabene merupakan bentuk pengamalan terhadap perintah Allah secara komprehensif sebagaimana firmanNya "masuklah kalian ke dalam Islam secara kaffah (total)", menjadi sulit.

d) Aliran Filsafat Pragmatisme Dalam Pendidikan

Pragmatisme yang tercabang dari Empirisme nampak jelas menggunakan Metode Ilmiah, yang dijadikan sebagai asas berpikir untuk segala bidang pemikiran, baik yang berkenaan dengan sains dan teknologi maupun ilmu-ilmu sosial kemasyarakatan. Ada beberapa hal yang ia kritik dan menjadi titik lemah dari pragmatism (Nizar, 2005).

Pertama, kritik dari segi landasan ideologi. Menurutnya, pragmatisme dilandaskan pada pemikiran dasar (Aqidah) pemisahan agama dari kehidupan (sekularisme). Hal ini nampak dari perkembangan historis kemunculan pragmatisme, yang merupakan perkembangan lebih lanjut dari Empirisme. Dengan demikian, dalam konteks ideologis, pragmatisme berarti menolak agama sebagai sumber ilmu pengetahuan. Aqidah pemisahan agama dari kehidupan adalah landasan ideologi kapitalisme. Kedua, kritik dari segi metode berpikir yang menggunakan metode ilmiah (Al-Attas, 2003).

Metode ini merupakan metode yang benar untuk objek-objek yang bersifat materi/fisik seperti halnya dalam sains dan teknologi. Tetapi menjadikan metode empirik sebagai landasan berpikir untuk segala sesuatu pemikiran adalah suatu kekeliruan, sebab yang seharusnya juga menjadi landasan pemikiran adalah metode akliyah/rasional (Ath Thariq Al Aqliyah), bukan hanya metode empirik. 
Ketiga, kritik terhadap pragmatisme itu sendiri. Pragmatisme adalah aliran yang mengukur kebenaran suatu ide dengan kegunaan praktis yang dihasilkannya untuk memenuhi kebutuhan manusia. Ide ini keliru dari tiga sisi: 1) pragmatisme mencampur adukkan kriteria kebenaran ide dengan kegunaan praktisnya; 2) pragmatisme menafikan peran akal manusia; 3) pragmatisme menimbulkan relativitas dan kenisbian kebenaran sesuai dengan perubahan subjek penilai ide baik individu, kelompok, dan masyarakat dan perubahan konteks waktu dan tempat.

\section{SIMPULAN DAN SARAN}

\section{A. Simpulan}

Berdasarkan pemaparan mengenai pemikiran Ali Ahmad Madkur tentang ilmu pengetahuan dalam islam, maka dapat disimpulkan bahwa istilah kurikulum berasal dari bahasa Prancis yaitu courier yang berarti to run, maksudnya adalah berlari. Sedangkan dalam bahasa Yunani kuno Kurikulum berasal dari kata curir yang artinya pelari dan curere artinya tempat berpacu atau tempat berlari. Sedangkan curriculum diartikan sebagai jarak yang harus ditempuh oleh pelari, sehingga kurikulum dalam pendidikan diartikan sebagai sejumlah pelajaran yang harus ditempuh atau diselesaikan oleh anak didik guna mendapatkan ijazah, akan tetapi pada perkembangannya. Kurikulum mencakup berbagai kegiatan yang diharapkan mampu mencapai tujuan dari pendidikan, dalam sistem pendidikan Islam, kurikulum dikenal dengan istilah "manhaj" yang berarti "jalan terang"adalah jalan yang harus dilalui oleh para pendidik untuk mengembangkan keterampilan pengetahuan dan sikap mereka. Bab kedua dari buku Manhaj al-Tarbiyah fi alTashawwur al-Islami karya Ali Ahmad Madkur ini berbicara tentang salah satu aspek fundamental dalam pendidikan yaitu aspek kurikulum, untuk membicarakan lebih lanjut tentang kurikulum, penyusun buku ini membicarkan lebih dahulu berbagai landasan teoritis fundamental yang menjadi bagian yang tidak terpisahkan dari konsepsi kurikulum. Aspek-aspek tersebut antara lain pemahaman dasar pendidikan, filsafat dan pendikan, teori-teori pendidikan, peranan ilmu dalam pendidikan. Terkait pokok pembahasan yang berhubungan dengan kurikulum, bab kedua dengan judul thabiah ma'rifah al-tashawwur al-islami memberikan gambaran yang komprehensif tentang ilmu pengetahuan dalam pandangan Islam, sebuah pemahaman yang didasarkan pada pe-mahaman alqur'an dan sunnah, lalu pada kajian historis terhadap pemikiran para ulama, kajian tokohtokoh muslim yang mem-punyai konsentrasi pada pendidikan, serta berbagai penelitian dari para ilmuan non muslim yang berkaitan dengan objek pendidikan Islam.

\section{B. Saran}

Penelitian ini merupakan kajian awal tentang pemikiran Ali Ahmad Madkur tentang ilmu pengetahuan dalam islam, sehingga diperlukan adanya tindak lanjut yang lebih mendalam dalam membahas landasan teori dan praktik dalam pemikiran Ali Ahmad Madkur tentang ilmu pengetahuan dalam islam, pada penelitian berikutnya bisa dilakukan penelitian yang lebih komprehensif terkait pemikiran Ali Ahmad Madkur tentang ilmu pengetahuan dalam islam.

\section{DAFTAR RUJUKAN}

Al-Attas. (2003). Filsafat dan Praktik Pendidikan Islam, terj. Hamid Fahmi dkk. Bandung: Mizan.

Al-Maududi. (1982). Al-Manhaj Al-Islamiy AlJadid li At-Tarbiyah wa At-Ta'lim. Beirut: AlMaktab Al-Islamiy.

Al-Misri. (1990). Lisanul Arab. Fairus Abadi. Kamus al-Muhit.

Apiyani, A. (2022). Implementasi Pengembangan Keprofesian Berkelanjutan (PKB) Guru Madrasah Dalam Meningkatkan Keprofesian. JIIP-Jurnal Ilmiah Ilmu Pendidikan, 5(2), 499-504.

Arifudin, 0. (2018). Pengaruh Pelatihan Dan Motivasi Terhadap Produktivitas Kerja Tenaga Kependidikan STIT Rakeyan Santang Karawang. MEA (Manajemen, Ekonomi, \& Akuntansi), 2(3), 209-218.

Arifudin, O. (2019). Manajemen Sistem Penjaminan Mutu Internal (SPMI) Sebagai Upaya Meningkatkan Mutu Perguruan Tinggi. MEA (Manajemen, Ekonomi, \& Akuntansi), 3(1), 161-169. 
Arifudin, 0. (2020). Psikologi Pendidikan (Tinjauan Teori Dan Praktis). Bandung: Widina Bhakti Persada.

Arifudin, 0. (2021). Konsep Dasar Pendidikan Anak Usia Dini. Bandung: Widina Bhakti Persada Bandung.

Bahri, A. S. (2021). Pengantar Penelitian Pendidikan (Sebuah Tinjauan Teori dan Praktis). Bandung: Widina Bhakti Persada.

Darmawan, I. P. A. (2021). Total Quality Management Dalam Dunia Pendidikan" Model, Teknik Dan Impementasi". Bandung: Widina Bhakti Persada Bandung.

Darmayani, S. (2021). Pembelajaran Digital. Bandung: Widina Bhakti Persada.

Dewey. (1966). Democracy And Education. New York: The Free Press.

Fatiyah. (1986). Sistem Pendidikan Islam Versi alGhazali, alih bahasa Fathurrahman dan Syamsudin. Bandung: PT.Al-Ma'arif.

Hasbi, I. (2021). Administrasi Pendidikan (Tinjauan Teori Dan Praktik). Bandung: Widina Bhakti Persada.

Madkur. (2002). Manhaj Tarbawi fi tashawur alislami. Cairo: Darul fikri 'arabi.

Na'im, Z. (2021). Manajemen Pendidikan Islam. Bandung : Widina Bhakti Persada.

Nasser, A. A. (2021). Sistem Penerimaan Siswa Baru Berbasis Web Dalam Meningkatkan Mutu Siswa Di Era Pandemi. Biormatika: Jurnal Ilmiah Fakultas Keguruan Dan Ilmu Pendidikan, 7(1), 100-109.
Nizar. (2005). Filsafat Pendidikan Islam: pendekatan historis, teoritis dan praktis. Jakarta: Ciputat Press.

Rahayu, Y. N. (2020). Program Linier (Teori Dan Aplikasi). Bandung : Widina Bhakti Persada.

Supriani, Y. (2022). Peran Manajemen Kepemimpinan dalam Pengelolaan Lembaga Pendidikan Islam. JIIP-Jurnal Ilmiah Ilmu Pendidikan, 5(1), 332-338.

Tafsir. (2003). Filsafat Umum Akal dan Hati Sejak Thales Sampai Capra. Bandung: Remaja Rosdakarya.

Tafsir. (2012). Ilmu Pendidikan Islam. Bandung: Remaja Rosdakarya.

Tanjung, R. (2019). Manajemen Pelayanan Prima Dalam Meningkatkan Kepuasan Mahasiswa Terhadap Layanan Pembelajaran (Studi Kasus di STIT Rakeyan Santang Karawang). MEA (Manajemen, Ekonomi, \& Akuntansi), 3(1), 234-242.

Tanjung, R. (2020). Pendampingan Usaha Oncom Dawuan Makanan Khas Kabupaten Subang Jawa Barat. Jurnal Ilmiah Pangabdhi, 6(2), 59-63.

Tanjung, R. (2022). Manajemen Penyelenggaraan Pendidikan Inklusi pada Lembaga Pendidikan Islam. JIIP-Jurnal Ilmiah Ilmu Pendidikan, 5(1), 339-348.

Ulfah, U. (2022). Kepemimpinan Pendidikan di Era Disrupsi. JIIP-Jurnal Ilmiah Ilmu Pendidikan, 5(1), 153-161. 